\title{
Bilateral Superior Radioulnar Synostosis: A Rare Congenital Anomaly
}

\author{
${ }^{1}$ Seema Sehmi, ${ }^{2}$ Maninder S Sehmi
}

\begin{abstract}
Introduction: Congenital radioulnar synostosis is a rare anomaly of the upper limb with functional limitations of the limb. However, it occurs more commonly than perceived and is often a part of syndromes, such as Crouzon, Apert's, and Poland's. The exact etiology is not clear, but there is genetic basis for the failure of differentiation between the radius and ulna.

Case report: A6-year-old child with pain and limited mobility of the elbow joint came to the outpatient department, Department of Orthopedics, Government Medical College Amritsar, Punjab, India. Plain X-ray anteroposterior and lateral views were taken that showed bilateral superior radioulnar synostosis.
\end{abstract}

Conclusion: Diagnostic imaging like radiological studies can help the surgeons to plan for surgery of radioulnar synostosis.

Keywords: Crouzon, Elbow, Poland, Radioulnar.

How to cite this article: Sehmi S, Sehmi MS. Bilateral Superior Radioulnar Synostosis: A Rare Congenital Anomaly. Curr Trends Diagn Treat 2017;1(2):89-90.

Source of support: Nil

Conflict of interest: None

\section{INTRODUCTION}

Congenital radioulnar synostosis was first described by Sandifort in $1793 .^{1}$ It is a rare congenital malformation with limited rotation of the forearm during daily routine activities. ${ }^{2,3}$ During embryonic life, the forearm is held in pronation position and this is the position in congenital radioulnar synostosis. ${ }^{4}$ The literature reports on approximately 350 cases of congenital radioulnar synostosis. ${ }^{5}$ However, this is the most common congenital functional disorder of the elbow joint. In 60 to $80 \%$ of cases, it is observed bilaterally. ${ }^{1}$ In $9 \%$ of cases, it runs in a family. ${ }^{5}$ In $25 \%$ of cases, this malformation is genetically conditioned. ${ }^{6}$

\footnotetext{
${ }^{1}$ Professor, ${ }^{2}$ Assistant Professor

${ }^{1}$ Department of Anatomy, Sri Guru Ram Das Institute of Medical Sciences \& Research, Amritsar, Punjab, India

${ }^{2}$ Department of Orthopedics, Government Medical College Amritsar, Punjab, India

Corresponding Author: Seema Sehmi, Professor, Department of Anatomy, Sri Guru Ram Das Institute of Medical Sciences \& Research, Amritsar, Punjab, India, Phone: +919914654354 e-mail: drseema16@gmail.com
}

It is commonly believed that this malformation is connected with chromosome $X$ aberrations. ${ }^{7}$ However, there are reports on cases of congenital radioulnar synostosis occurring in chromosome $\mathrm{Y}$ aberrations. ${ }^{8}$

\section{CASE REPORT}

A 6-year-old male child came to the outpatient department, Government Medical college, Amritsar, Punjab, India, with the history of pain at the shoulder joint and difficulty in supination of both upper limbs. Child was quite healthy with no other congenital anomaly. There was no history of trauma to the elbow joint. Mother of the child gave no history of fever or drug intake during pregnancy. The X-ray anteroposterior as well as lateral views of both upper limbs were taken to rule out superior and inferior radioulnar synostosis (Fig. 1). The child in the present case was diagnosed as bilateral superior radioulnar synostosis.

\section{DISCUSSION}

Radioulnar synostosis is regarded as an anomaly of longitudinal segmentation. It is presumed that some factor inhibits the interzonal mesenchyme between the cartilage analog of the developing radius and ulna from undergoing dissolution during the 7 th week of intrauterine life. Thus, the interzonal mesenchyme persists and undergoes chondrification, ossification, and eventually synostosis. The proximal one-third of the forearm is the most common site of involvement. About $40 \%$ of the cases
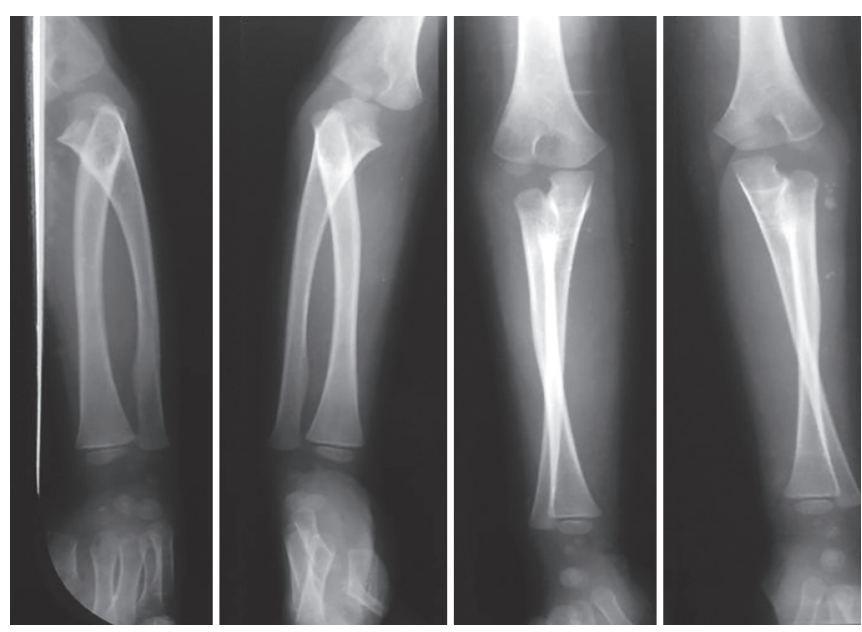

Fig. 1: Anteroposterior and lateral views of $X$-rays of both forearms showing bilateral superior radioulnar synostosis 
are unilateral and $60 \%$ bilateral. Males are affected more commonly than females. These children usually present with functional problems like difficulty in holding objects, two-handed posture, and problems in dressing or feeding. They are often seen holding objects, such as coins with a backhanded posture. ${ }^{9}$ Wilkie ${ }^{4}$ had described two types of synostosis based on radiographic appearance. Type I represents true radioulnar synostosis in which the radius and ulna are smoothly fused at their proximal ends and this extends for a variable distance distally. Type II is represented by congenital dislocation of head of radius in addition to type I deformity. Our patient has type I deformity. Cleary and Omer ${ }^{10}$ identified radiologically four patterns of radioulnar synostosis. Type I does not involve bone and is associated with normal radial head. Type II has visible osseous synostosis. Type III has osseous synostosis with a hypoplastic and posteriorly dislocated radial head. Type IV has short-osseous synostosis with an anterior dislocated radial head. The present case has type II radioulnar synostosis as per Cleary's classification. Patient with unilateral or bilateral deformities with less than $30^{\circ}$ of pronation generally do not require surgery. With more than $60^{\circ}$ or more of fixed pronation, there is obvious functional impairment in children with both unilateral and bilateral radioulnar synostosis. ${ }^{10}$ For those with between 30 and $60^{\circ}$ of pronation, one must carefully individualize functional limitation and esthetic needs. Our patient had fixed pronation bilaterally. Various surgical options have been proposed to restore the correct position and mobility. These include resection of synostosis, ${ }^{4}$ insertion of swivel apparatuses, reconstruction with interpositional material, ${ }^{11}$ or rotational osteotomy through or distal to synostosis mass. ${ }^{12}$ Resection of synostosis, insertion of swivel apparatuses, and reconstruction with interpositional materials have been inconsistent over time because of bone overgrowth around implant materials and angulation of the forearm distal to the osteotomy. Therefore, these procedures are of historical interest only. ${ }^{13}$ Derotational osteotomy through the area of synostosis is the functionally satisfactory procedure. ${ }^{14}$ While deciding on the method of treatment, it is extremely helpful to do diagnostics imaging procedures and especially use the results of computed tomography (CT) with three-dimensional and planar reconstructions. The CT allows for a detailed visualization of the spatial relations, which will help in the precise planning of the surgical procedure. ${ }^{15}$

\section{CONCLUSION}

Congenital radioulnar synostosis is a rare congenital anomaly of the upper limb. Embryologically, it is regarded as an anomaly of longitudinal segmentation. It may be associated with chromosomal aberrations. If the deformity is mild in nature, the child can compensate well with adjusted movements of the adjacent joints. Derotational osteotomy can help the patients with severe bony deformity. Sometimes, poor surgical outcomes are also noted.

\section{REFERENCES}

1. Lescault E, Mulligan J, Williams G. Congenital radioulnar synostosis in an active duty soldier: case report and literature review. Mil Med 2000 May;165(5):425-428.

2. Kao HK, Chen HC, Chen HT. Congenital radioulnar synostosis treated using microvascular free fascio-fat flap. Chang Gung Med J 2005 Feb;28(2):117-122.

3. Masuko T, Kato H, Minami A, Inoue M, Hirayama T. Surgical treatment of acute elbow flexion contracture in patients with congenital proximal radioulnar synostosis. A report of two cases. J Bone Joint Surg Am 2004 Jul;86-A(7):1528-1533.

4. Wilkie DPD. Congenital radioulnar synostosis. Br J Surg 1914; 1:366-375.

5. Fakoor M. Radioulnar synostosis in a father and his 5 year old daughter. Pak J Med Sci 2006;22(2):191-193.

6. Yammine K, Salon A, Pouliquen JC. Congeniatal radioulnar synostisis. Study of a series of 37 children and adolescents. Chir Main 1998;17(4):300-308.

7. Elliott AM, Kibria L, Reed MH. The developmental spectrum of proximal radioulnar synostosis. Skeletal Radiol 2010 Jan;39(1):49-54.

8. Syed AA, Quinton R. Congenital radioulnar synostosis, azoospermia and pseudodicentric $\mathrm{Y}$ chromosome. Fertil Steril 2008 Aug;90(2):425-426.

9. Mital MA. Congenital radio-ulnas synostosis and congenital dislocation of the radial head. Orthop Clin North Am 1976 Apr;7(2):375-383.

10. Cleary JE, Omer GE Jr. Congenital proximal radio ulnar synostosis. Natural history and functional assessment. J Bone Joint Surg 1985 Apr;67(4):539-545.

11. Simmons BP, Southmayd WW, Riseborough EJ. Congenital radio ulnar synostosis. J Hand Surg 1983 Nov;8(6):829-838.

12. Green WT, Mital MA. Congenital radio-ulnar synostosis: surgical treatment. J Bone Joint Surg Am 1979 Jul;61(5):738-774.

13. Kelikian H, Doumanian A. Swivel for proximal radio-ulnar synostosis. J Bone Joint Surg Am 1957 Jul;39-A(4):945-952.

14. Khalil I, Vizkelety T. Osteotomy of the synostosis mass for the treatment of Congenital radio-ulnar synostosis. Arch Orthop Trauma Surg 1993 Dec;113(1):20-22.

15. Siemianowicz A, Wawrzynek W, Besler K. Congenital radioulnar synostosis - case report. Pol J Radiol 2010 OctDec;75(4):51-54 